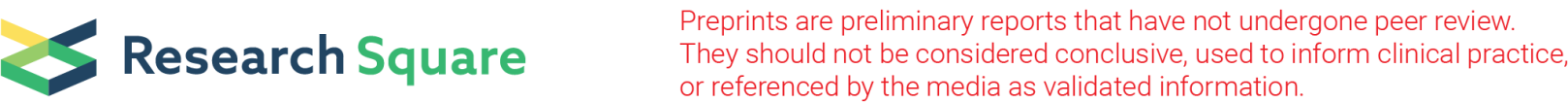

\section{World Delirium Awareness Day 2019, delirium and risk of falls in the hospital setting}

\section{Rozina Shekhar}

South Western Sydney Local Health District

Kaye Denise Rolls ( $\square$ kaye.rolls@westernsydney.edu.au )

South Western Sydney Local Health District Population Health https://orcid.org/0000-0003-1807-6620

\section{Briony Chasle}

South Western Sydney Local Health District

\section{Katrina Stott}

South Western Sydney Local Health District

\section{Vaulina Vueti}

South Western Sydney Local Health District

\section{Vicki Deane}

South Western Sydney Local Health District

\section{Renee Edmonds}

South Western Sydney Local Health District

\section{Margaret Moseley}

South Western Sydney Local Health District

\section{Bernadette Shepherd}

South Western Sydney Local Health District

\section{Mandana Mayahi-Neysi}

South Western Sydney Local Health District

\section{Carol Wilson}

South Western Sydney Local Health District

\section{Novjot Sandu}

South Western Sydney Local Health District Jennifer Phillips

South Western Sydney Local Health District

\section{Lynda Marov}

South Western Sydney Local Health District

\section{Sara Carr}

South Western Sydney Local Health District K'Sandra Richardson

South Western Sydney Local Health District Kathy McGuire 
South Western Sydney Local Health District

Poumansing Gujraz

South Western Sydney Local Health District

\section{Binita Kumar}

South Western Sydney Local Health District

\section{Daniella Jankulovski}

South Western Sydney Local Health District

\section{Kylie Dixon}

South Western Sydney Local Health District

\section{Yashwani Lata}

South Western Sydney Local Health District

\section{Rinsy Zachariah}

South Western Sydney Local Health District

\section{Bradley Warner}

South Western Sydney Local Health District

\section{Steven A Frost}

Western Sydney University

\section{Research article}

\section{Keywords:}

Posted Date: August 22nd, 2019

DOl: https://doi.org/10.21203/rs.2.13394/v1

License: (c) (1) This work is licensed under a Creative Commons Attribution 4.0 International License. Read Full License 


\section{Abstract}

Background Delirium is an acute change in cognition, common among older hospitalized patients, however, patients of all ages are at risk of delirium during a hospital stay. The International Federation of Delirium Societies promotes, each year, a World Delirium Awareness Day, to raise the awareness of, not just recognizing delirium in the hospital setting, but ensuring interventions are in place to prevent the development of delirium. Hospitalized patients with delirium have increased risk of adverse events such as falls, pressure injury, malnutrition, increased length of stay, increased health care costs, and mortality. This clinical audit aimed to estimate the risk of a subsequent fall, following an acute episode of inhospital delirium, across a broad cross-sectional of clinical settings. Methods Seventeen adult acute inpatient wards across a health district, undertook an audit of the number of admitted patients who had had at least one episode of delirium since being admitted to hospital. Using the hospital-based incident management reporting system, the rates of subsequent falls was compared between delirium and nondelirium patients. Results Fifty of the 473 patients $(11.4 \%)$ were identified by the nursing staff to have had at least one episode of delirium since admission. The proportion of fallers among the delirium and non-delirium patients were $10 \%$ and $2 \%$, respectively $(p=0.004)$. The rate of falls per 1000 patient days was 6.45 (95\% confidence interval (Cl) 2.1 to 15.1) among delirium patients, compared to $2.12(95 \% \mathrm{Cl}$ 1.0 to 4.0 ) among patients without delirium. The risk of falling among delirium patients was 4.25 higher compared to non-delirium patients (adjusted hazard ratio $(\mathrm{HR})=4.25,95 \% \mathrm{Cl} 1.26$ to 14.39). Conclusion This clinical audit has been able to show that an acute episode of delirium increases the risk of an inhospital fall fourfold. Importantly, these results have highlighted the need for a hospital wide approach, to not just in identifying delirium, but the need to have interventions in place to reduce the risk of delirium. In other words, delirium prevention should be 'core business' of all nursing care, across the acute hospital setting.

\section{Background}

Delirium is an acute change in cognition, common among older hospitalized patients [1], however, patients of all ages are at risk [2-4]. Unfortunately, delirium is often not recognized, and therefore poorly treated in the hospital setting [5-7]. For this reason, each year the International Federation of Delirium Societies promotes a World Delirium Awareness Day, to raise the awareness of, not just recognizing delirium in the hospital setting, but ensuring interventions are in place to prevent the development of delirium.

Hospitalized patients with delirium have increased risk of adverse events such as falls, pressure injury, malnutrition, increased length of stay, increased health care costs, and mortality $[1,2,8]$. Falls have been described as one of the most commonly reported adverse events among the elderly admitted to hospital. In particular, falls in the acute hospital setting can result in serious injuries, prolong hospital stay, and can be associated with unexpected death [9-11]. Approximately $2 \%$ to $12 \%$ of patients fall during a hospital 
stay [10], with this rate increasing with age, and has been reported to be as high as $46 \%$ among patients cared for in stroke rehabilitation units [12]. However, consistent strong evidence for the benefit of many interventions currently used in the hospital setting, to prevents falls, has not been found when systematically reviewed by experts in this area - in fact, it was concluded a "multifactorial intervention may reduce the risk of falls" in the acute hospital setting $[9,13]$. Considering that most modern acute hospitals actively attempt to identify patients at the greatest risk of falls, and institute a number of interventions to prevent a fall, the conclusion reached by the Cochrane Review (quoted above) is quite sobering, and may indicate that only marginal gains may be obtained by implementation of further interventions to reduce falls in the acute hospital setting. It is for this reason, that we became interested in widening the scope of falls prevention when discovering the relationship between an episode of delirium in the hospital setting and a subsequent fall has been previously described [14-16]. However, previous work in this area was limited to retrospective review of the clinical notes of in-hospital fallers, finding documented evidence of delirium prior to a fall, or some prospective studies of elderly patients in the hospital setting, among which an association between delirium and falls was observed [17-19]. No studies to date have explored the relationship between an acute episode of delirium and subsequent falls risk across a broad cross-sectional of clinical settings, not just among elderly hospitalized patients. For this reason, this clinical audit was specifically aimed at estimating the risk of subsequent fall, following an acute episode of in-hospital delirium, across a broad cross-sectional of clinical settings.

\section{Methods}

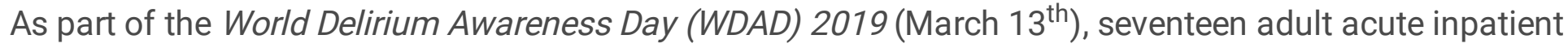
wards across the (redacted for review) health district, undertook an audit of the number of admitted patients who had had at least one episode of delirium since being admitted to hospital. Patients from these seventeen wards were then followed until discharge or an incident fall. This project is part of an ongoing program of nursing-led investigation, across our local health district, concentrating on Frailty, Falls, Fracture and Delirium (The Triple-FD program).

\section{Subject and setting}

The South Western Sydney Local Health District provides public hospital care for approximately a million residents, with five acute care hospitals, with approximately 230,000 separations each year. The seventeen wards [no. of wards] included in our clinical audit, offer adult acute inpatient care in the following clinical areas: (1) Aged care [3]; (2) Medical [3]; (3) Surgical [7]; Mixed medical/surgical [2]; and, (4) Rehabilitation [2]. All inpatients of these seventeen wards on the morning of WDAD (Wednesday, March $\left.13^{\text {th }}, 2019\right)$ where included in the audit. Inpatients on the $13^{\text {th }}$ of March, 2019 across the seventeen wards were followed-up for one of the following events: (1) an incident fall; (2) discharge without fall; or, until the $30^{\text {th }}$ of April, 2019, without falling or being discharged from hospital. 


\section{Identification of delirium}

All acute hospitals across our local health district use the Confusion Assessment Method (CAM) to identify acute episodes of delirium among any patient who appears to be disorientated or confused, or who has any change in behaviour, or level of consciousness [20]. The CAM is based on four main area of assessment: (1) acute onset and fluctuating course (Is there evidence of an acute change in mental status from baseline? If so, did the abnormal behaviour fluctuate during the day?); (2) Inattention (did the patient have difficulty focussing attention during the interview?); (3) Disorganised thinking (was the patient's thinking disorganised?); and, (4) Altered level of consciousness (overall, how would you rate the patient's level of consciousness?) [20].

\section{Identification of falls}

Reporting of in-hospital falls (regardless of injury) is mandatory for all clinical staff, and are entered into a dedicated Incident Information Management System (IIMS)[21] as part of routine documentation. All inhospital falls up until April $30^{\text {th }}$, among clinical audit participants were included.

\section{Ethical considerations}

Using our state-wide guide on assessing ethical risk [22], and due to the nature of this clinical audit using routinely collected data, that constitutes usual patient care and documentation, ethical review was considered to be unwarranted for the purposes of publication of the results of this clinical audit.

\section{Statistical methods}

Characteristics of patients included in the clinical audit are presented as descriptive statistics, based on delirium status. Rates of delirium and incident falls during follow-up, based on type of ward and delirium status, were calculated per 1000 patient days, and 95\% confidence intervals were also calculated, comparison of groups was undertaken using Poisson regression [23]. The risk (presented as hazard ratios (HR), and 95\% confidence intervals) of an incident fall during follow-up and at least one episode of acute delirium since admission was estimated using Cox's proportional hazards models [24]. Verification of the proportional hazards assumption of the Cox models was based on a visual inspection of smoothed Schoenfeld residual plots [25]. All analyses were performed using the R language for statistical computing [26]. 


\section{Results}

The characteristics of the 437 patients included in the WDAD 2019 (March $13^{\text {th }}$ ) clinical audit of the incidence of delirium since admission are presented in Table 1. Fifty of the 473 patients (11.4\%) were identified by the nursing staff to have had at least one episode of delirium since admission. The age of patients ranged from 17 to 101 years, patients with delirium were older (82 years versus 70 years, $p<$ $0.001)$, and more likely to be female $(14 \%$ versus $9 \%, p=0.076)$. The highest rates of delirium were reported in the Aged Care setting (32\%), and lowest rates were reported in the mixed medical/surgical wards. Fourteen incident falls were reported, up until the $30^{\text {th }}$ of April 2019, the median time of follow-up was 6 days (IQR 1-16), and the proportion of fallers among the delirium and non-delirium patients were $10 \%$ and $2 \%$, respectively $(p=0.004)$. The rate of falls per 1000 patient days was $6.45(95 \% \mathrm{Cl} 2.1$ to 15.1) among delirium patients, compared to 2.12 (95\% $\mathrm{Cl} 1.0$ to 4.0$)$ among patients without delirium ( $\mathrm{p}=$ 0.046). Overall 4 deaths were reported among the 437 patients ( 3 versus $1, p=0.310$, delirium and nondelirium patients, respectively).

The rates (per 1000 acute bed days) of delirium and incident falls based on type of ward are presented in Table 2. For example, the highest rate of delirium, per 1000 acute bed days, was observed in the aged care setting, 13.9 (95\% $\mathrm{Cl} 8.0$ to 22.6 ), and the lowest rate in the mixed medical/surgical wards, 2.5 (95\% $\mathrm{Cl} 0.1$ to 13.6.9). The highest rate of fall, per 1000 acute bed days of follow-up was observed in the mixed medical/surgical wards, $4.9(95 \% \mathrm{Cl} 0.6$ to 17.7$)$, and the lowest fall rate in the aged care setting, 1.7 (95\% $\mathrm{Cl} 0.2,6.3)$.

Kaplan-Meier plots of the cumulative risk of falling, based on delirium status are presented in Figure 1. Both crude and adjusted (adjusted for sex, age, and ward type) risk of falling during follow-up among delirium patients compared to non-delirium patients are presented in Table 3. The risk of falling among delirium patients was 4.25 higher compared to non-delirium patients ( $\mathrm{HR}=4.25,95 \% \mathrm{Cl} 1.26$ to 14.39), after adjusting for sex, age and ward type. The $c$-statistic (concordance) for the delirium only and adjusted model were 0.622 and 0.729 , respectively.

\section{Discussion}

This clinical audit of adult patients admitted to a diverse group of hospitals wards across a local health district, has been able to show that an acute episode of delirium increases the risk, fourfold, of an inhospital fall. Importantly, this observed increased risk of falling in the hospital setting, highlights the need for a hospital wide approach, to not just in identifying delirium, but the need to have interventions in place to reduce the risk of delirium, in an attempt to reduce associated adverse events such as a fall. 
The findings of this clinical audit confirm the results of a number of observational studies [16], and delirium prevention trials, that not only had shown an increased risk of falls among hospitalised patients with delirium, but a reduced risk of falling among delirium prevention intervention groups when compared to usual care [27]. Earlier work in this area had highlighted an association between falling and delirium in the hospital setting, but was limited to retrospective review of the clinical notes of patients who had fallen $[14,15]$, or prospective observation of elderly patients cared for in the aged care setting. Importantly, this clinical audit has included a broad cross-sectional of adult acute inpatients and shown a strong relationship between an acute episode of delirium and risk of a subsequent fall.

The results of this clinical audit need to be considered in the context of some potential limitations. Firstly, the identification of delirium in the hospital setting is often subject to some error. However, the majority of this error is related to false negatives (sensitivity of 0.81 ) when the CAM had been compared to a more exhaustive assessment of delirium using the Diagnostic and Statistical Manual of Mental Disorders (DSM IV) [28]. Importantly, false positives rates have been estimated to be low (1\%) when also compared to DSM IV [28]. The consequences of this would be that across the wards which were included in our clinical audit, delirium rates may be under estimated, and using the method suggested by Kelsey [29] (using the above estimates of sensitivity and specificity of 0.81 and 0.99 , respectively), the overall observed rate of $11.4 \%$ would increase to approximately $13 \%$. There is no suggestion that the misclassification of delirium would be related to subsequent fall status, and therefore this error would be considered non-differential in nature, among fallers and non-fallers. In other words, we expect our estimates of the risk for falls related to delirium status would not have been biased by the under recognition of delirium, due to the equality of error (non-differential error) in the recognition of delirium between patients subsequently falling and those who did not fall. However, there may also be some under-reporting of falls, and in a similar manner we expect this to be non-differential in nature between delirium and non-delirium patients.

A strength of this clinical audit if that we have been able to include a diverse cross-section of hospitalised patients receiving, aged care, surgical, medical and rehabilitation, representing the diverse population of patients that are at risk of experiencing an acute episode of delirium in the hospital setting. Therefore, we propose that our results highlight the need to ensure delirium prevention should be 'core business' of all nursing care across the hospital, not just in the aged care setting. As, an increasing body of evidence supports the benefits of non-pharmacological, multicomponent nurse-led interventions to reduce the incidence, severity and duration of delirium among adults cared for in the acute hospital setting $[1,30$, 31]. 
The clinical implications of recognising the importance of delirium prevention in the hospital setting, in an attempt to improve the quality and safety of all patients, is not a novel by any means [2]. However, highlighting to all nursing staff across the hospital the importance of delirium prevention, not just in the aged care setting, but among medical and surgical specialties will ensure that good quality and safe care of patients at risk delirium and falls, can be guaranteed, irrespective of the wards setting of care.

\section{Conclusions}

This clinical audit has been able to show that an acute episode of delirium increases the risk of an inhospital fall fourfold. Importantly, these results have highlighted the need for a hospital wide approach, to not just in identifying delirium in the hospital setting, but the need to have interventions in place to reduce the risk of delirium, in an attempt to reduce the risk of associated adverse events such as a fall. In other words, delirium prevention should be 'core business', of all nursing care across the acute hospital setting.

\section{Declarations}

Ethics approval and consent to participate - This study was a clinical audit and formal ethics approval was not sort based on health department policy [22]

Consent for publication - not applicable

Availability of data and materials - The datasets used and/or analysed during the current study are available from the corresponding author on reasonable request.

Competing interests - The author(s) declare(s) that they have no competing interests

Funding_- no specific funding was used for this study with all authors contributions undertaken as part of their usual employment

Author contributions - All authors contributed to the conception of the study: SF, RS and KR(olls) designed the study; Coordination of data collection and data acquisition BC, KS, VV, VD, RE, MM, BS, CW, NS, JP, LM, SC, KR, KMcG, PG, BK, DJ, KD, YL, RZ; Study coordination RS and BW; Data interpretation and analyses SAF; Drafting and revision of manuscript KR(olls), RS and SAF; all authors approved of manuscript

Acknowledgments - the authors would like to thank the nursing staff and nursing unit managers on each of the 17 wards, and the nursing executive of each of the hospitals for making this audit possible

\section{Abbreviations}

CAM - Confusion assessment method

$\mathrm{Cl}$ - confidence intervals 
DSM IV - Statistical Manual of mental disorders

HR - Hazard ratio

IQR - interquartile range

WDAD - World delirium awareness day

\section{References}

1. Inouye SK, Westendorp RG, Saczynski JS: Delirium in elderly people. Lancet 2014; 383(9920):911922.

2. Australian Commission on Safety and Quality in Health Care: Delirium Clinical Care standards. In. Edited by Health Do. Australia; 2016.

3. Inouye SK: Predisposing and precipitating factors for delirium in hospitalized older patients. Dement Geriatr Cogn Disord 1999; 10(5):393-400.

4. Siddiqi N, House AO, Holmes JD: Occurrence and outcome of delirium in medical in-patients: a systematic literature review. Age Ageing 2006; 35(4):350-364.

5. Collins N, Blanchard MR, Tookman A, Sampson EL: Detection of delirium in the acute hospital. Age Ageing 2010; 39(1):131-135.

6. Han JH, Zimmerman EE, Cutler N, Schnelle J, Morandi A, Dittus RS, Storrow AB, Ely EW: Delirium in older emergency department patients: recognition, risk factors, and psychomotor subtypes. Acad Emerg Med 2009; 16(3):193-200.

7. Iseli RK, Brand C, Telford M, LoGiudice D: Delirium in elderly general medical inpatients: a prospective study. Intern Med J 2007; 37(12):806-811.

8. Agency for Clinical Innovation Aged Care Health Network: Key Principles for Care of Confused Hospitalised Older Persons. In.; 2015.

9. Cameron ID, Gillespie LD, Robertson MC, Murray GR, Hill KD, Cumming RG, Kerse N: Interventions for preventing falls in older people in care facilities and hospitals. Cochrane Database Syst Rev 2012; 12:CD005465.

10. Coussement J, De Paepe L, Schwendimann R, Denhaerynck K, Dejaeger E, Milisen K: Interventions for preventing falls in acute- and chronic-care hospitals: a systematic review and meta-analysis. $\mathrm{J} \mathrm{Am}$ Geriatr Soc 2008; 56(1):29-36.

11. Szymaniak S: Accurate falls risk assessment and interventions for preventing falls in patients in the acute care setting within a private hospital in a large capital city: a best practice implementation project. JBI Database System Rev Implement Rep 2015; 13(9):386-406.

12. Rensink M, Schuurmans $M$, Lindeman $E$, Hafsteinsdottir TB: [Falls: incidence and risk factors after stroke. A systematic literature review]. Tijdschr Gerontol Geriatr 2009; 40(4):156-167. 
13. Cameron ID, Dyer SM, Panagoda CE, Murray GR, Hill KD, Cumming RG, Kerse N: Interventions for preventing falls in older people in care facilities and hospitals. Cochrane Database Syst Rev 2018; 9:CD005465.

14. Babine RL, Hyrkas KE, Bachand DA, Chapman JL, Fuller VJ, Honess CA, Wierman HR: Falls in A Tertiary Care Hospital-Association With Delirium: A Replication Study. Psychosomatics 2016; 57(3):273-282.

15. Lakatos BE, Capasso V, Mitchell MT, Kilroy SM, Lussier-Cushing M, Sumner L, Repper-Delisi J, Kelleher EP, Delisle LA, Cruz C et al: Falls in the general hospital: association with delirium, advanced age, and specific surgical procedures. Psychosomatics 2009; 50(3):218-226.

16. Sillner AY, Holle CL, Rudolph JL: The Overlap Between Falls and Delirium in Hospitalized Older Adults: A Systematic Review. Clin Geriatr Med 2019; 35(2):221-236.

17. Basic D, Hartwell TJ: Falls in hospital and new placement in a nursing home among older people hospitalized with acute illness. Clin Interv Aging 2015; 10:1637-1643.

18. Mazur K, Wilczynski K, Szewieczek J: Geriatric falls in the context of a hospital fall prevention program: delirium, low body mass index, and other risk factors. Clin Interv Aging 2016; 11:1253-1261.

19. Stenvall M, Olofsson B, Lundstrom M, Englund U, Borssen B, Svensson O, Nyberg L, Gustafson Y: A multidisciplinary, multifactorial intervention program reduces postoperative falls and injuries after femoral neck fracture. Osteoporos Int 2007; 18(2):167-175.

20. Inouye SK, van Dyck CH, Alessi CA, Balkin S, Siegal AP, Horwitz RI: Clarifying confusion: the confusion assessment method. A new method for detection of delirium. Ann Intern Med 1990; 113(12):941-948.

21. Health N: Incident Management Policy. New South Wales. In.: NSW Health; 2014.

22. NSW H: Human Research Ethics Committees - Quality Improvement \& Ethical Review: A Practice Guide for NSW. In. Edited by Research OfHaM. North Sydney, NSW: NSW Health; 2018.

23. Breslow NE, Day NE: Statistical methods in cancer research. Lyon: International Agency for Research on Cancer; 1980.

24. Cox DR: Regression models and life tables. J R Stat Soc (B) 1972; 34:187-220.

25. Schoenfeld D: Partial residuals for the proportional hazards regression model. Biometrika 1982; 69(1):239-241.

26. R Core Team: R: A Language and Environment for Statistical Computing. In. Vienna, Austria: R Foundation for Statistical Computing; 2017.

27. Hshieh TT, Yue J, Oh E, Puelle M, Dowal S, Travison T, Inouye SK: Effectiveness of multicomponent nonpharmacological delirium interventions: a meta-analysis. JAMA Intern Med 2015; 175(4):512520.

28. Shi Q, Warren L, Saposnik G, Macdermid JC: Confusion assessment method: a systematic review and meta-analysis of diagnostic accuracy. Neuropsychiatr Dis Treat 2013; 9:1359-1370. 
29. Kelsey JL, Thompson WD, Evans AS: Methods in observational epidemiology. New York: Oxford University Press; 1986.

30. Hshieh TT, Yue J, Oh E, Puelle M, Dowal S, Travison T, Inouye SK: Effectiveness of multicomponent nonpharmacological delirium interventions: a meta-analysis. JAMA internal medicine 2015; 175(4):512-520.

31. Kang J, Lee M, Ko H, Kim S, Yun S, Jeong Y, Cho YJJocc: Effect of nonpharmacological interventions for the prevention of delirium in the intensive care unit: A systematic review and meta-analysis. Journal of critical care 2018; 48:372-384.

\section{Tables}

Table 1. Characteristics of patients included in the World Delirium Awareness Day audit of Delirium since admission.

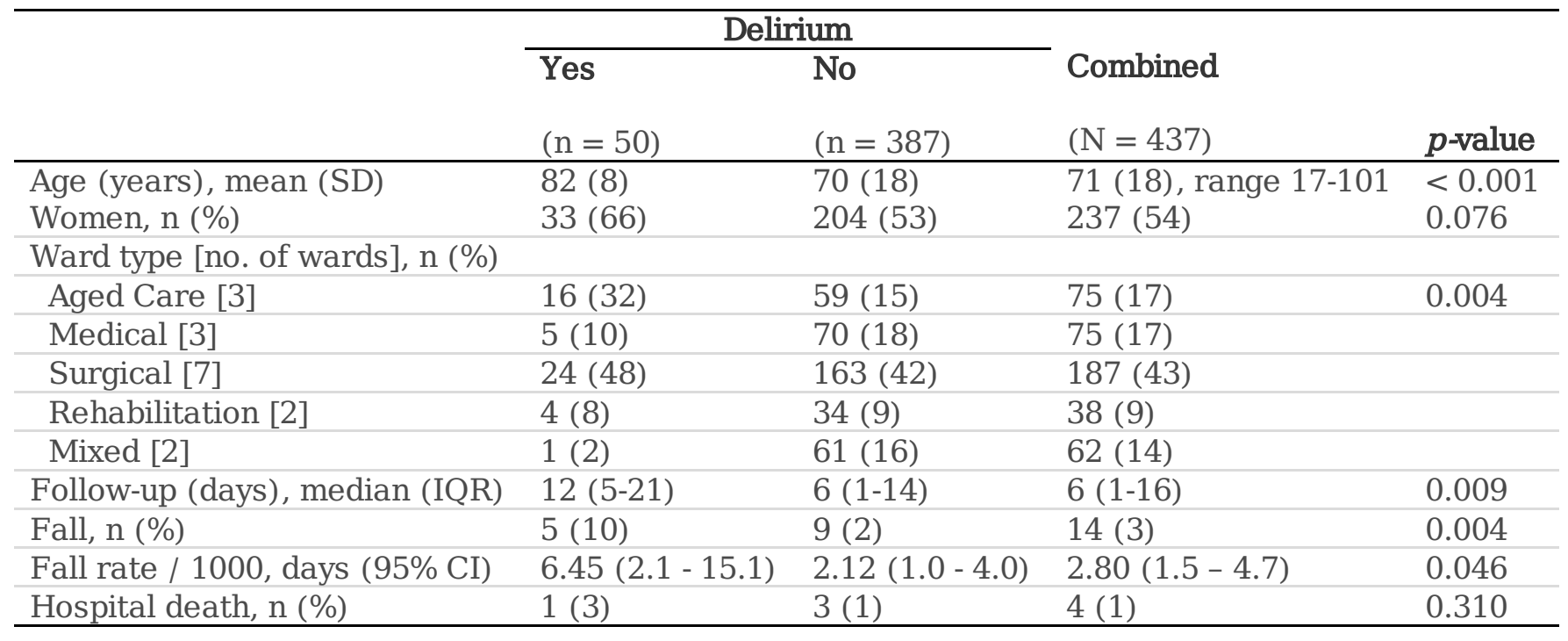

Table 2. Incidence rates (per 1000 acute bed days) of delirium and falls, based on ward type.

\begin{tabular}{lllll}
\hline & Delirium & Falls & \\
& & & & \\
Ward type [no. of pts] & $n$, rate $(95 \% C I)$ & $p$-value & $n$, rate $(95 \%$ CI $)$ & $p$-value ${ }^{1}$ \\
\hline Aged care [75] & $16,13.9(8.0,22.6)$ & 0.104 & $2,1.7(0.2,6.3)$ & 0.897 \\
\hline Medical [75] & $5,6.6(2.1,15.4)$ & & $2,2.7(0.3,9.6)$ & \\
\hline Surgical [187] & $24,11.7(7.5,17.4)$ & & $6,2.9(1.1,6.4)$ & \\
\hline Rehab [38] & $4,6.0(1.6,15.5)$ & $2,3.0(0.4,10.9)$ & \\
\hline Mixed [62] & $1,2.44(0.1,13.6)$ & $2,4.9(0.6,17.7)$ & \\
\hline
\end{tabular}

${ }^{1} p$-values from Likelihood Ratio-tests from Poisson regression models of rates, using the lowest rate ward type as the reference group. 
Table 3. Risk of in-hospital fall based on delirium status.

\begin{tabular}{lcclc}
\hline & \multicolumn{3}{c}{ Hazard Ratio (95\% CI) } \\
\cline { 2 - 5 } & \multicolumn{1}{c}{ Crude } & $p$-value & Adjusted & $p$-value \\
\hline Delirium & $3.18(1.06-9.51)$ & 0.039 & $4.25(1.26-14.39)$ & 0.020 \\
Male (versus female) & $1.50(0.52-4.33)$ & 0.452 & $1.57(0.53-4.68)$ & 0.418 \\
\hline Age (10-years increase) & $0.99(0.71-1.38)$ & 0.952 & $0.96(0.66-1.40)$ & 0.836 \\
\hline Ward type & & & & \\
\hline Aged care & $1.0($ ref $)$ & & & 0.521 \\
\hline Medical & $1.48(0.21-10.6)$ & 0.693 & $1.96(0.25-15.4)$ & 0.538 \\
\hline Surgical & $1.58(0.32-7.8)$ & 0.578 & $1.67(0.33-8.5)$ & 0.480 \\
\hline Rehab & $1.60(0.22-11.4)$ & 0.641 & $2.05(0.27-15.5)$ & 0.488 \\
\hline Mixed & $2.31(0.32-16.7)$ & 0.406 & $3.66(0.46-29.2)$ & 0.221 \\
\hline
\end{tabular}

Delirium alone concordance $($ c-statistic $)=0.622$, adjusted model concordance $=0.729$.

\section{Figures}

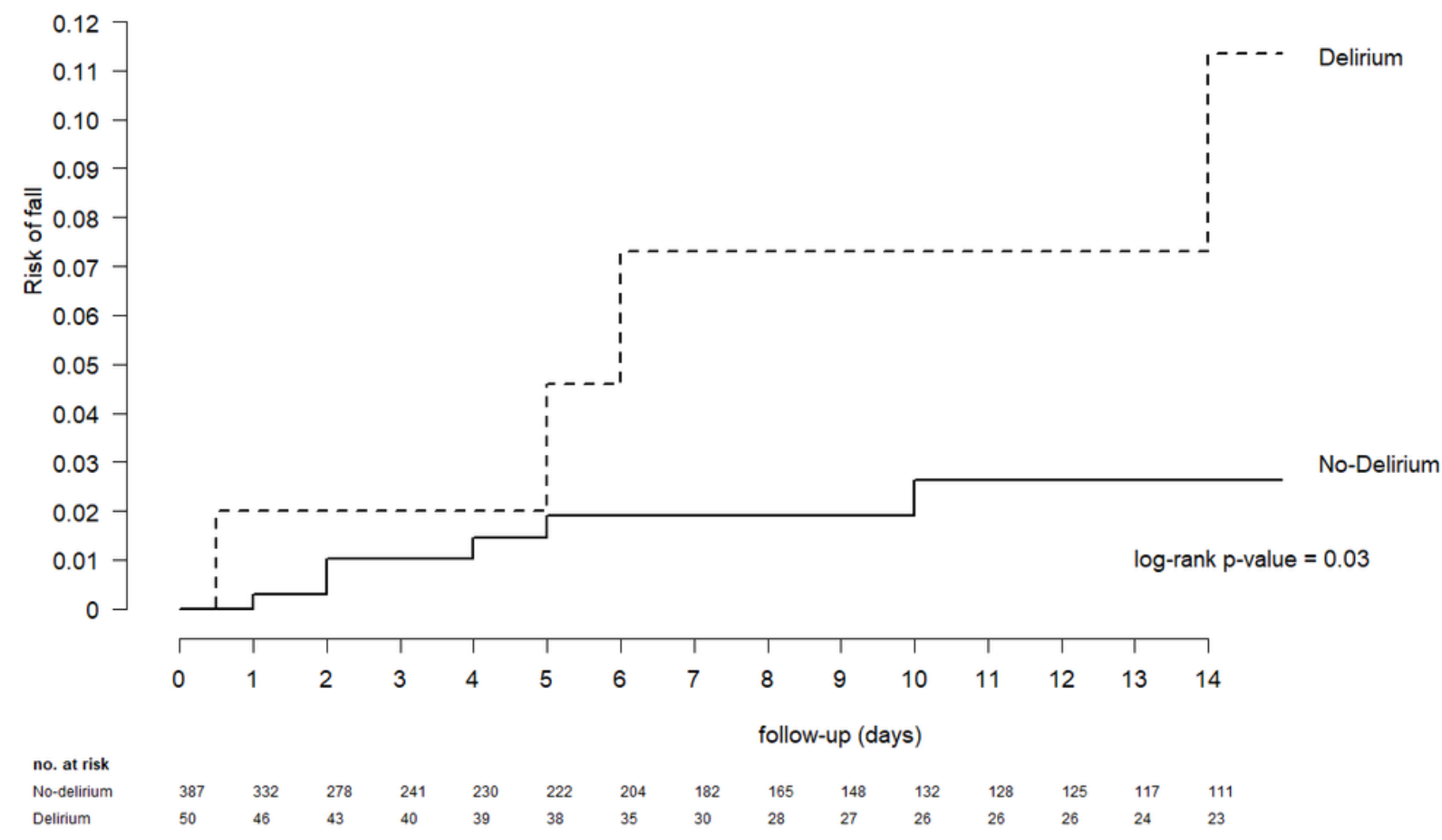


Figure 1

Kaplan-Meier plot of the risk of fall based on delirium status. 